\title{
Analisa dan Perancangan Tata Kelola Akses Internet Gratis pada Café Roose Menggunakan Mikrotik Rb 750
}

\author{
Ari Syaripudin \\ Fakultas Teknik, Universitas Pamulang, \\ Jl. Surya Kencana No.1 Pamulang Barat, Tangerang Selatan \\ e-mail: dosen00671@unpam.ac.id
}

\begin{abstract}
Free internet access provided at a café is expected to increase the interest of café visitors. Cafe Roose provides free internet access to consumers, it is expected that with free internet access, the number of visitors to the café will increase. Free internet access is spread through WIFI devices that use a $2.4 \mathrm{Ghz}$ frequency. This wifi is used because almost all communication devices are used such as Smart Phones and laptops using WIFI. The problem that arises is that internet access on public networks requires high protection so as not to be misused, the increasing number of users causes the internet access to be unstable. Officers also cannot control the use of internet access. From these problems, the governance of free internet access was made on roose café using mikrotik rb 750.
\end{abstract}

Kata Kunci: Internet, Wifi, Mikrotik

\section{Pendahuluan}

Tidak dapat dipungkiri kebutuhan akan internet sudah tidak dapat dipisahkan lagi dari kebutuhan pokok manusia. Kemajuan teknologi berdampak terhadap meninggkatnya penggunaan internet dalam proses pertukaran informasi. Internet meniadakan dinding pemisah jarak dalam komunikasi, orang dari belahan bumi manapun dapat melakukan pertukaran informasi dengan biaya murah melalui internet. Hal ini berpengaruh terhadap kebutuhan yang tinggi terhadap akses internet.

Pada saat ini Akses internet dijadikan bagian dari strategi marketing para pengusaha rumah makan, cafe dan fasilitas publik lainnya untuk menarik calon konsumen. Banyak cafe yang memberikan akses internet gratis kepada konsumennya atau sering disebut HOTSPOT. HOTSPOT menggunakan jaringan nirkabel seperti WIFI yang menggunakan frekuensi $2.4 \mathrm{Ghz}$. Wifi ini digunakan karena hampir semua perngakat komunikasi yang digunkan seperti Smart Phone sudah menggunakan WIFI.

Cafe Roose menyediakan akses internet gratis kepada konsumennya, diharapkan dengan adanya akses internet gratis, jumlah pengunjung café tersebut meningkat. Akses internet yang diberikan menggunakan modem wireless, dengan keamanan WPA2 yang ada pada modem wireles tersebut. Pengunjung yang datang ke cafe dapat menggunakan akses internet dengan cara meminta password modem wireless tersebut kepada petugas. Permasalahan yang muncul adalah jaringan publik membutuhkan proteksi yang tinggi supaya tidak disalah gunakan, semakin banyaknya pengguna menyebabkan akses internet yang didapat menjadi tidak stabil. Petugas juga tidak dapat melakukan kontrol terhadap penggunaan internet.

Mikrotik merupakan perangkat jaringan yang memiliki banyak fitur seperti manajemen bandwith, HOTSPOT, DHCP untuk IP Address Client, dan Manajement User. Mikrotik sering digunakan untuk meningkatkan proteksi terhadap keamanan pada jaringan komputer. Manajemen bandwith pada mikrotik dapat meningkatkan kestabilan akses internet. Manajemen user pada mikrotik dapat meningkatkan kontrol terhadap pengguna jaringan komputer.

Berdasarkan uraian di atas maka dibuatlah penelitian dengan judul "ANALISA DAN PERANCANGAN TATA KELOLA INTERNET GRATIS PADA CAFÉ ROOSE MENGGUNAKAN MIKROTIK RB 750.

\section{Metode Penelitian}

Metode penelitian yang digunakan pada penelitian ini adalah Network Develovment Life Cycle atau disingkat NDLC. Diagram Network Develovment Life Cycle digambarkan sebagai berikut; 


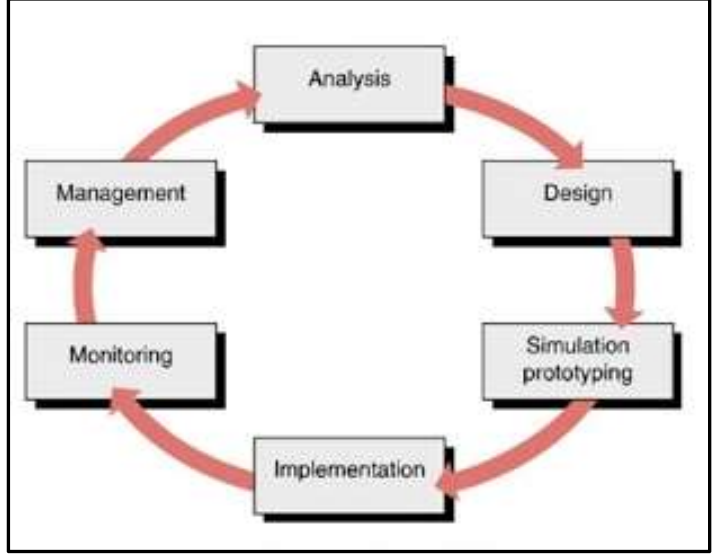

Gambar 1. Diagram alir pada Metode Network Develovment Life Cycle

a. Tahap Analisis

Pada tahap Analisis peneliti menganalisa permasalahan yang ingin diselesaikan dan perangkat keras yang di butuhkan dalam pengembangan sistem ini.

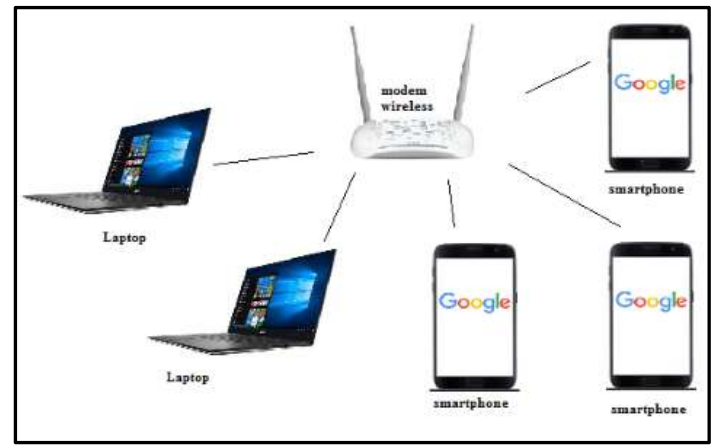

Gambar 2. komponen pada sistem berjalan

b. Tahap Perancangan

Perancangan Toplogi yang digunakan saat ini setelah menggunakan mikrotik dan acces point.

c. Tahap Simulasi

Uji coba dilakukan pada sistem skala kecil yaitu koneksi pada Smartphone petugas café dan komputer admin café.

d. Tahap Implementasi

Sistem yang baru akan menerapkan fitur DHCP Server, bandwidth management, hotspot, User Manager, dan Network Address Translation menggunakan Winbox.

e. Tahap Monitoring

Monitoring dilakukan dengan memantau aktifitas user, melakukan pengukuran bandwith pada perangkat yang terkoneksi, memastikan pengguna aktif sesuai dengan daftar pengguna yang terdaftar dan memantau trafic apakah sudah sudah sesuai atau belum.

f. Tahap Manajemen
Berikut langkah-langkah yang akan dilakukan pada tahap ini ;

1. Mengaktifkan DHCP Server agar setiap device yang terhubung mendapatkan IP secara dinamis tanpa perlu melakukan pengisiian ip secara manual.

2. Mengaktifkan login HOTSPOT agar hanya pelanggan atau karyawan yang diberikan hak akses yang dapat mengakses jaringan tersebut.

3. Manajemen bandwith dengan menyesuaikan kecepatan akses yg dimiliki café Roose. Supaya jaringan stabil.

4. Melakukan backup pengaturan mikrotik, untuk mencegah kerusakan terhadap jaringan dan dapat dengan mudah dikembalikan ke pengaturan semula.

\section{Hasil dan Pembahasan}

Café Roose memiliki akses internet yang digunakan untuk kebutuhan internal perusahan dan juga untuk jaringan Hotspot yang di bangun untuk meningkatkan minat pengunjung café tersebut. Kecepatan akses internet café Roose sebesar 10 mbps yang bersal dari ISP Indyhome. Kecepatan akses tersebut tidak dikelola dengan baik sehingga menjadi tidak maksimal. Penggunaan IP Static pada device internal perusahaan dan ip dynamic pada jaringan hotspot membuat koneksi tidak stabil karena terkadang terjadi duplikasi IP address. Tidak ada juga kontrol terhadap pengguna jaringan Hotspot. Pengguna jaringan hotspot di berikan password kemudian connect selesai. Café Roose menggunakan perangkat yang diberikan oleh IndyHome yang terdiri dari modem wireless dan android tv. Pada komputer perusahaan yang terhubung menggunakan wireless yang ditambahkan pada komputer tersebut untuk dapat terhubung.

Implementasi Hotspot Server pada café Roose menggunakan Perangkat mikrotik RB 750, acces point, kabel UTP. Kabel UTP digunakan hanya untuk menghubungkan modem indyhome, mikrotik dan Acces Point sedangkan koneksi client menggunakan perangkat wireless. Metode pengalamatan yang digunakan adalah pengalamatan dengan menggunakan IP versi 4.

\section{a. Identifikasi Masalah}

Dari wawancara dan pengumpulan data di lapangan masalah yang dihadapi adalah sbb:

1. Tidak adanya proteksi yang tinggi terhadap jaringan sehingga orang lain dapat dengan 
mudah mengakses jaringan pada café tersebut.

2. Tidak adanya pengaturan terhadap pemberian IP addres dan manajemen bandwith sehingga koneksi menjadi tidak stabil.

3. Tidak adanya kontrol terhadap pengguna sehingga pegawai café tidak bisa melakukan pengawasan terhadap pengguna.

\section{b. Rumusan Masalah}

Rumusan masalah berdasarkan identifikasi masalah diatas adal sbb:

1. Bagaimana membuat proteksi yang tinggi terhadap jaringan sehingga orang lain tidak dapat dengan mudah mengakses jaringan pada café tersebut?

2. Bagaimana membuat pengaturan terhadap IP addres dan manajemen bandwith sehingga koneksi menjadi stabil?

3. Bagaiman membuat kontrol terhadap pengguna sehingga pegawai café/admin jaringan bisa melakukan pengawasan terhadap pengguna?

\section{Desain}

Desain setelah menambahkan mikrotik dan Acces Point pada café Roose menjadi sbb:

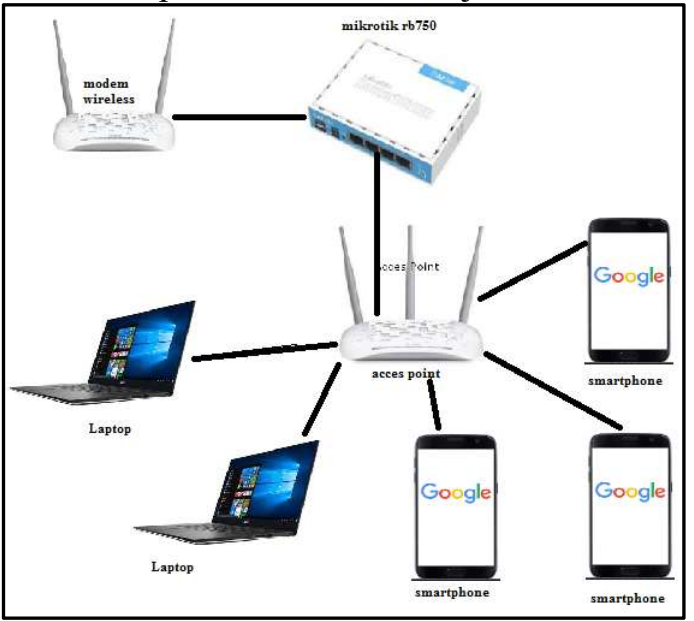

Gambar 3. Desain jaringan pada café Roose

\section{Simulasi}

Simulasi dilakukan pada sistem skala kecil yaitu koneksi pada Smartphone petugas café dan komputer admin café, Setelah dilakukan tahap Implementasi. Implementation Software

Imlementasi dilakukan dengan menghubungkan perangkat sesuai dengan topologi perancangan kemudian melakuakn pengaturan mikrotik memlui remote dari komputer yang terhubung ke mikrotik. Remote dilakukan menggunak bantuan aplikasi Winbox. Selanjutnya melakukan pengaturan di dalam winbox tersebut. Berikut langkah-langkah pengaturan;

\section{a. Penggunaan Winbox}

Jalankan Aplikasi winbox kemudian pada kolom Connect To masukan IP address atau Mac Address Mikrotik RB750, masukan juga Password pada kolom Password jika mikrotik tersebut menggunakan password.

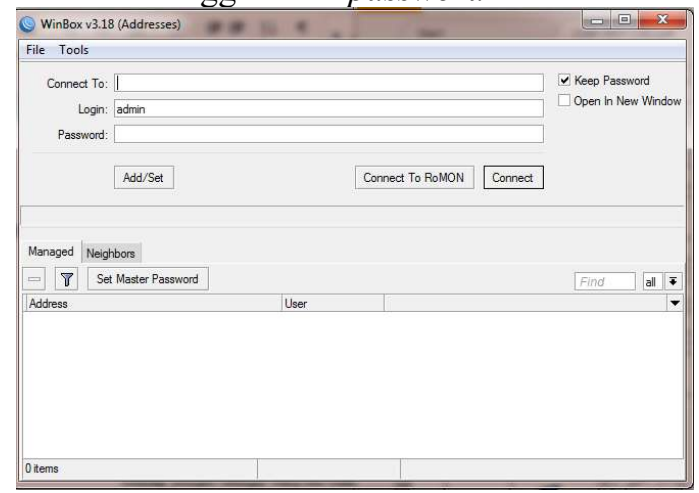

Gambar 4. Antarmuka Aplikasi Winbox Versi 3.18

\section{b. Pengaturan pada mikrotik}

Setelah aplikasi winbox terhubung dengan Mikrotik lakukan langkah berikut:

\section{Pengaturan IP address Either1 Modem}

Pilih Menu $I P>$ Addresses kemudin klit tanda "+ " pada Address List seperti pada gambar berikut;

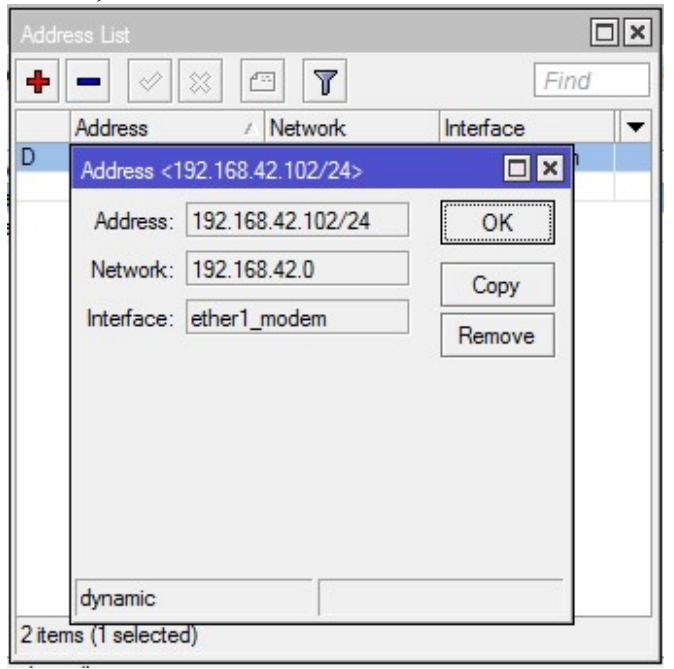

Gambar 5. Pengaturan IP Modem

Setting IP Address Either2_AP

Lakukan sama seperti cara di atas pilih either2 masukan IP seperti gambar berikut; 


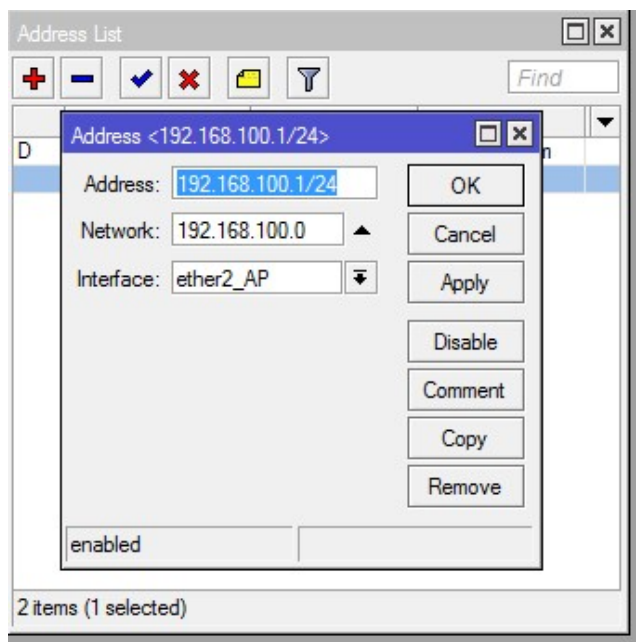

Gambar 6. Pengaturan IP untuk Acces Point

\section{Pengaturan Pada Menu Domain Name Server} Setting DNS Seperti gambar berikut;

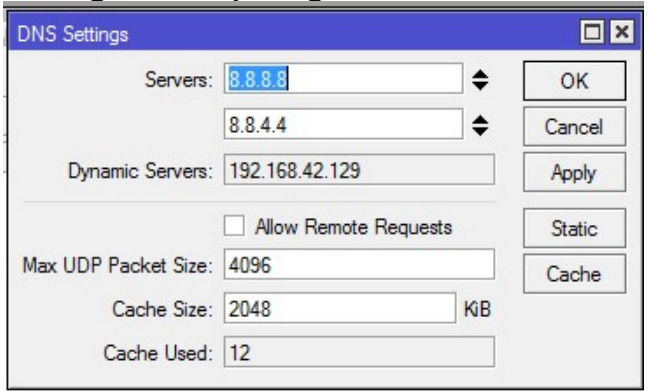

Gambar 7. Pengaturan pada menu Domain Name Server

\section{Pengaturan pada menu $\mathrm{DHCP}$}

Langkah Selanjutnya memilih menu DHCP Server. DHCP Server berfungsi untuk memberikan IP Address otomatis pada setiap perangkat yang terhubung dalam jaringan hotspot.

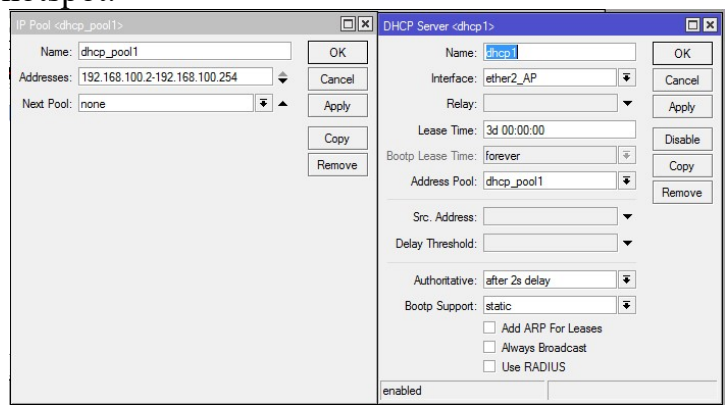

Gambar 8. Pengaturan pada menu DHCP

\section{Konfiigurasi Routes}

Pilih menu Routes, pada kolom IP gateway masukan 192.168.42.125 (IP yang digunakan pada Modem), seperti ditunjukan gambar berikut ini;

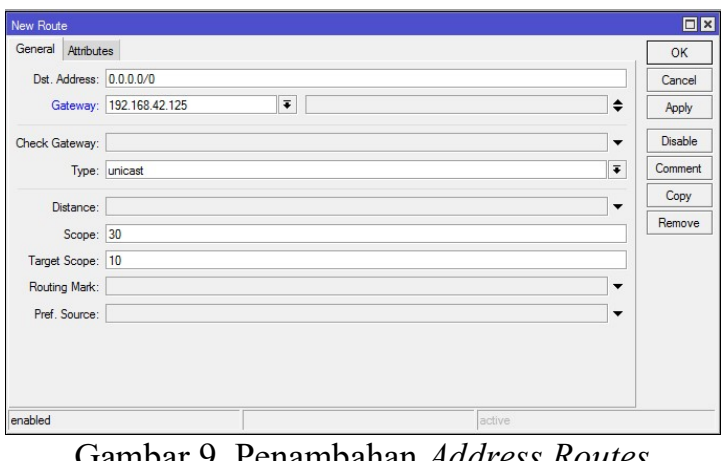

Gambar 9. Penambahan Address Routes

Pengaturan firewall pada Network Address Translation

Pengaturan firewall pada Network Address Translation perlu dilakukan agar seluruh client pada jaringan café Roose mendapatkan akses internet.

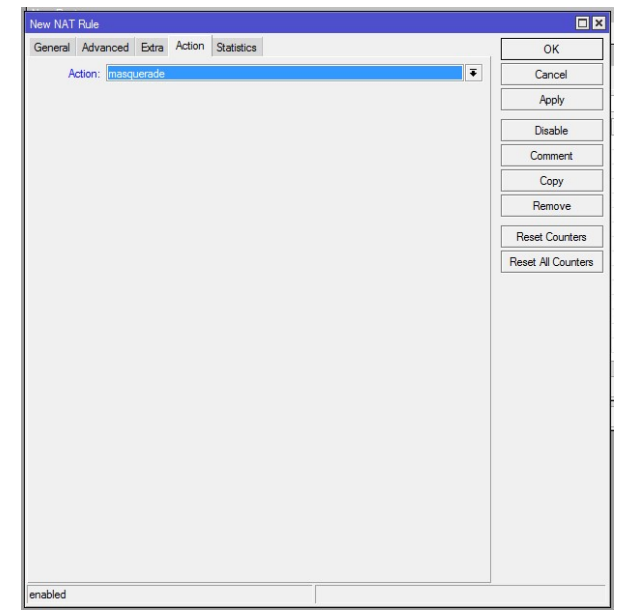

Gambar 10. Pengaturan Firewall pada Network Address Translation

\section{Pengaturan pada menu Hotspot}

pengaturan hotspot ditunjukan pada gambar berikut;

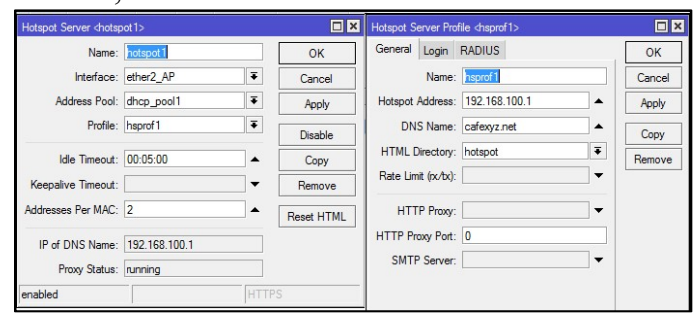

Gambar 11. Pengaturan Hotspot pada Mikrotik

\section{Pengaturan Bandwith}

Pengaturan bandwith diperlukan untuk membatasi penggunaan bandwith, sehingga tidak ada pengguna internet yang menggunakan bandwith secara curang.

Langkahnya adalah sebagai berikut; 
Pilih submenu Simple Queues pada menu Queues kemudiaan isi kolom bandwith seseuai gambar berikut;

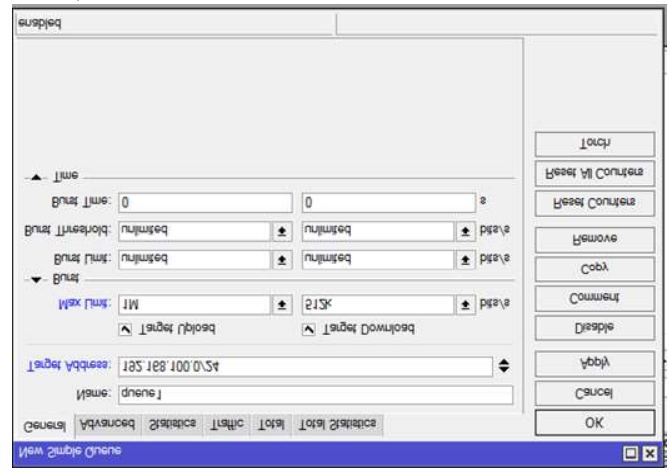

Gambar 12. Pengaturan bandwith Hotspot

\section{Membuat User}

Pembuatan user diperlukan agar client dapat menggunakan hotspot melului username dan password yang di berikan. Berikut gambar pembuatan user;

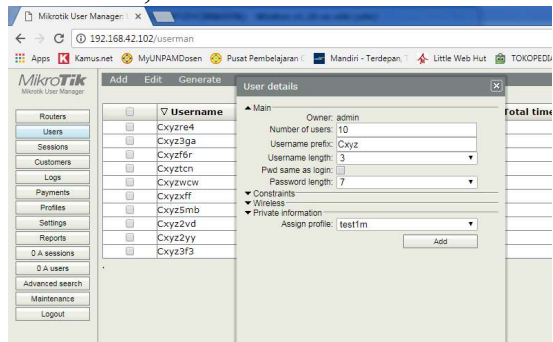

Gambar 13. Pembuatan User melalui Userman

\section{Pemantauan pada router}

Pemantauan dilakukan dengan melihat grafik pemakaian bandwith pada masing-masing client apakah sudah sesuai aturan yang diterapkan pada mikrotik.

\section{Pengelolaan}

Pengelolalan terhadap sistem yang baru berkaitan dengan pengelolaan jumlah pemakai, bandwith masing-masing pemakai pada café roose dan backup terhadap pengaturan pada mikrotik yang sudah dilakukan.

\section{Kesimpulan} berikut;

Kesimpulan dari penelitian ini sebagai

1. sistem baru memiliki proteksi tinggi, sehingga kemungkinan penyalahgunaan acces internet menurun.

2. Banyaknya pengguna tidak mempengaruhi kestabilan akses internet karena pemberian ip dynamic dan manajement bandwith meminimalkan hal itu.

3. Petugas juga dapat melakukan kontrol terhadap penggunaan hotspot melalui remote mikrotik melaui

\section{Daftar Pustaka}

Edy Winarno St, M. E. (2014). Membuat Jaringan Komputer Di Windows \& Linux. Jakarta: Elex Media Komputindo.

Hardana, \& Irvantino, I. (2011). Konfigurasi Wireless Routerboard Mikrotik. Yogyakarta: Andi.

Musajid, A. (2015). Jaringan Virtual : Mikrotik, Cisco \& Juniper Dengan Gns3 - Solusi Belajar Jaringan Tanpa Hardware. Jakarta: Jasakom .

Purbo, O. W. (2011). Jaringan Wireless Di Dunia Berkembang - Panduan Praktis Perencanaan Dan Pembangunan Infrastruktur Komunikasi. Yogyakarta: Andi.

Purbo, O. W. (2018). Internet-Tcp/Ip: Konsep Dan Implementasi. Yogyakarta: Andi.

Satya, I. A. (2007). Mikrotik Winbox. Jakarta: Datakom Lintas Buana.

Yani, A. (2009). Panduan Membangun Jaringan Komputer. Depok: Kawan Pustaka. 